\title{
An Empirical Analysis of the Development of Russian Innovation Economy - Based on the Solow Growth Model
}

\author{
Yun Zuo \\ School of International Trade and Economics, Dongbei University of Finance and Economics, Dalian 116025, Liaoning, China \\ Email: zuoyun85@mail.ru
}

\begin{abstract}
Russia's long-term dependence on the development model of the resource economy can achieve the construction of the "oil curse", and the innovative economy has become an inevitable choice for its economic development. Measures to optimize the environment and mechanisms for innovation. In order to travel the actual situation of Russia's innovative economic development, this article uses the Solow model to formulate time data from 2000 to 2018, constructs an economic development model of Russian economic innovation, and constructs an economic development model of technological innovation. The results show that Russia's technological innovation has a negative growth effect, and there are still upcoming events in the development of Russia's innovation economy.
\end{abstract}

Keywords: innovation economy, resource-dependent economy, technological innovation, technological progress

\section{Introduction}

In the unstoppable daily mode of economic development, promoting the development of the world economy has become a common problem faced by mankind. The internal inevitable requirement of the model from the extensional development to the quality connotation ${ }^{[1]}$. In the context of the iterative transformation of new technology and the continued downturn of the world economy, the role of technology in driving economic growth, especially the violent impact of the new crown pneumonia epidemic in 2020 on the economy, has spawned new knowledge and new knowledge worldwide. Effective use, innovation, technology and innovation have become an important driving force for the recovery of the epidemic economy and adjustment of the economic structure in the post-epidemic era.

As early as 20 years ago, Kuzk, a Correspondence Academician of the Russian Institute of Economic Strategies and the Russian Academy of Sciences, comprehensively analyzed his own innovative economic development strategy. The 2008 financial crisis was a turning point for Russia's economic growth. The Russian government suddenly popularized the fragility of the export-oriented economic growth method and the lack of resources. The transitional economic development model became a long-term national strategy for the country's economic development in the same year. ${ }^{[2]}$ The US government profited the "Russian Economic and Social Long-term Development Strategy by 2020" and established the country's Minister of Innovation and Development Strategy. Ulinana, Russia must explore the development of an innovative economy, saying that "other than an innovative economy, don't choose other people." In April 211, in the government work report, we should continue to support innovation. In December, the Russian government issued the "Russian Innovation and Development Strategy by 2020", which determined the goals and measures for Russia's innovation and development. Innovation and other methods have promoted the transformation of a resource-dependent economy model to an innovative reproduction model. Assessing the development of the new economy at this stage will allow us to grasp the "pulse" of future economic development and make effective recommendations.

\section{Literature review}

The research on the development of Russia's innovation economy is roughly analyzed from three different perspectives: First, from the perspective of national strategy, it studies the implementation of Russia's innovation economy development strategy. Qi Wenhai discussed the background, goals, and policy measures of the development of Russia's innovation strategy, and proposed that the implementation of the innovation economy development strategy is an inevitable choice for the country's future economic development. Xu Yuanfeng and Ren Gang ${ }^{[3]}$ believe that the resource-dependent economic model is the main obstacle to Russia's economic development, and proposed that the innovative economy should be realized through the development of human capital, the cultivation of market mechanisms and the promotion of technological innovation. Deng Hua and Diao Xiuhua analyzed the strategic goals and tasks of Russia's innovation and development, and successively proposed safeguard measures in terms of policy support, infrastructure construction, scientific research funding, and human input. The second is to study the Russian national innovation capability and evaluation system from a systematic perspective, 
so as to make policy recommendations for the development of the innovation economy. Diao Xiuhua ${ }^{[4]}$ pointed out that the development of innovation economy cannot be separated from the improvement of national innovation capability, and analyzed the path of national innovation capability development from the perspective of innovation input, innovation output and innovation potential. Guo Xiaoqiong commented on the effects of the implementation of innovative economic policies and measures such as the reform of scientific research institutions, intellectual property rights and venture capital. Xing Guofan $^{[5]}$ and Zhou Jingyan analyzed the current situation and direction of the development of high-tech industries, and pointed out that the implementation of innovation policies has improved Russia's innovation capabilities to a certain extent, but the resource economy is still the main way of Russian economic growth for a certain period of time. Ye Huijie ${ }^{[6]}$ put forward reasonable suggestions on innovation and development in the areas of innovation environment, scientific research personnel training, enterprise innovation and innovation cluster development, and international cooperation. The third is to study the environment, status quo and performance issues of the development of Russian innovation economy with the development of scientific and technological innovation as the starting point. Rokinov, Dyzhina, and Bekotov analyzed Russia's science and technology policy, science and technology development capabilities and prospects, and science and technology security development. Hao Yun and Fu Jingjun ${ }^{[7]}$ started from measuring innovation capability indicators, analyzed the development trend of Russian science and technology innovation, and pointed out that the improvement of the national innovation mechanism and innovation environment provided conditions for the development of Russian science and technology innovation and achieved certain results.

To sum up, the existing literature has analyzed the development of the innovation economy in Russia from different angles, but most of the research focuses on the discussion of theoretical facts and policy comments and suggestions. There are few empirical studies on the performance of the innovation economy. This research will analyze from this perspective, which reflects the innovation of this article to a certain extent.

\section{Model construction}

\subsection{Model setting}

The core driving force of the innovation economy is scientific and technological progress ${ }^{[8]}$. Based on the Solow growth model, this article examines the performance of Russia's innovation economy development by measuring the contribution rate of scientific and technological progress. In 1956, Robert Solow studied and analyzed the production function on the basis of his predecessors and found that there was a difference between the economic growth brought about by physical capital and labor Solow residual value. Subsequently, he completed two papers on economic growth ${ }^{[9]}$ and economic growth accounting methods ${ }^{[10]}$, and proposed an improved model of the C-D production function-the Solow growth model on the basis of the predecessors. The model describes that under the assumptions of Harold's neutral technological progress, constant returns to scale, and diminishing marginal returns of capital, a country's sustained economic expansion depends on three factors, namely capital, labor, and technology. The growth comes down to technological progress, that is, the increase in total factor productivity (TFP).

This article sets the production function as:

$$
Y_{t}=A_{t} K_{t}^{\alpha} L_{t}^{\beta}
$$

Among them, $\mathrm{Y}$ is total output, $\mathrm{A}$ is technological progress, $\mathrm{L}$ is labor input, $\mathrm{K}$ is capital input, and $\alpha$ and $\beta$ are the output elasticities of labor and capital, respectively. Take the logarithm of both sides of formula (1) at the same time to obtain

$$
\ln Y_{t}=\ln A+\alpha \ln K_{t}+\beta \ln L_{t}+\varepsilon_{t}
$$

Taking into account the availability of data and the need for data processing, according to the basic assumptions of the Solow model, formula (2) is transformed into:

$$
\ln \frac{Y_{t}}{L_{t}}=\ln A+\alpha \ln \frac{K_{t}}{L_{t}}+\varepsilon_{t}
$$

\subsection{Variable selection and data sources}

The data in this article comes from the database of the Russian Federal Statistical Office, and the annual report data from 
2000 to 2018 is selected for analysis. The total economic output Y, select GDP data to represent the variable of economic growth, in order to obtain comparable data, it is flattened. The amount of capital investment $\mathrm{K}$ refers to the total capital investment at a certain time. It is represented by the fixed asset investment of the whole society. Also in order to reduce the adverse effects of price changes, it is converted by the fixed asset price index. The variable $\mathrm{L}$ is the amount of labor input. In order to reflect the actual amount of labor input as much as possible, the endogenous variable of human capital is introduced here, and the number of employees in Russia is selected for calculation.

Refer to the accumulation method of years of education adopted by most scholars ${ }^{[1]}$, namely

$$
L_{t}=\sum_{i=1}^{3} L E_{i t} h_{i}
$$

Among them, $\mathrm{Lt}$ is the amount of human capital input in year $\mathrm{t}$, and $\mathrm{i}$ is the three levels of labor divided according to the three levels of Russian school education. $\mathrm{i}=1$, 2, and 3 respectively represent the elementary level with 4 years of education, the middle level with 11 years of education, and the higher level with 16 years of education. LEit is the labor input (employed number) of the $\mathrm{i}$-th academic level in year $\mathrm{t}$, and hi is the weight of the human capital level of the i-th academic level, which is expressed in terms of years of education.

\section{Empirical analysis and calculation results}

\subsection{Stationarity test}

In order to avoid the phenomenon of spurious regression in the time series, the ADF unit root test was performed on the data of the three variables of capital, labor, and technological progress. The results are shown in Table 1 below. Each variable in the model is zero-order single integer. Perform cointegration analysis.

Table 1. Variable stationarity test results

\begin{tabular}{ccccccc}
\hline Variable & ADF & $1 \%$ critical value & $5 \%$ critical value & $10 \%$ critical value & P & Stationarity \\
\hline $\ln \mathrm{Y}$ & -3.765589 & -3.92035 & -3.065585 & -2.673459 & 0.0135 & stable \\
$\ln \mathrm{stable}$ & -3.040391 & -2.660551 & 0.0432 & 0.0278 & stable \\
$\ln \mathrm{A}$ & -3.117303 & -3.857386 & -3.857386 & -3.040391 & -2.660551 & \\
\hline
\end{tabular}

\subsection{Regression analysis}

Perform OLS regression analysis on formula (3), and get:

$$
\ln \frac{Y}{L}=0.727327+0.593222 \ln A_{t-2}+0.966602 \ln \frac{K}{L}
$$

$$
\begin{array}{lll}
(65.39063) & (1.936126) \\
\mathrm{R}^{2}=0.988277 & \mathrm{~F}=590.1218
\end{array}
$$

From the regression results, the $\mathrm{R}^{2}$ value is 0.988277 , and the adjusted goodness of fit is 0.986602 , indicating that the regression goodness of fit is very high; the $\mathrm{F}$ value is greater than the critical statistical value of $\mathrm{F}$, and the corresponding $\mathrm{P}$ value of 0.0000 is less than 0.01 , indicating that the regression model has a very good With good explanatory power, the model is significantly established; the results of the $\mathrm{T}$ test show that the variable $\ln \mathrm{Y} / \mathrm{L}$ and the variable $\operatorname{lnK} / \mathrm{L}$ test pass at a significant level of 0.01 , indicating that capital and labor are significantly related to output.

\subsection{Cointegration test}

In order to measure whether the model is in equilibrium for a long time, the unit root test is performed on the residual sequence obtained by the regression:

Table 2. Cointegration test results

\begin{tabular}{ccccccc}
\hline Variable & ADF & $1 \%$ critical value & $5 \%$ critical value & $10 \%$ critical value & P & Stationarity \\
\hline Residual error & -1.903123 & -2.728252 & -1.96627 & -1.605026 & 0.0567 & stable \\
\hline
\end{tabular}


Table 2 shows that the residual sequence ECM passes the unit root test at the 5\% significance level, and its $\mathrm{P}$ value is less than 0.1 . It can be seen that the residual sequence is stable, and the null hypothesis that there is no cointegration relationship can be rejected. It can be seen from the equation that when the long-term per capita capital investment increases by $1 \%$, the per capita GDP will increase by about $0.97 \%$, and the promotion of technological progress to economic growth will lag behind by two periods.

\subsection{Measurement results}

According to the results, calculate the output elasticity of capital $\alpha=0.033398$, and the output elasticity of labor $\beta=$ 0.966602. For formula (2), $\Delta \mathrm{Y}_{t} / \mathrm{Y}_{t}=\Delta \mathrm{A}_{\mathrm{t}} / \mathrm{A}_{\mathrm{t}}+\alpha \Delta \mathrm{K}_{\mathrm{t}} / \mathrm{K}_{\mathrm{t}}+\beta \Delta \mathrm{L}_{\mathrm{t}} / \mathrm{L}_{\mathrm{t}}$ is derived from the differential knowledge, where $\mathrm{y}=\Delta \mathrm{Y}_{\mathrm{t}} / \mathrm{Y}_{\mathrm{t}}$, $\mathrm{a}=\Delta \mathrm{A}_{\mathrm{t}} / \mathrm{A}_{\mathrm{t}}, \mathrm{k}=\Delta \mathrm{K}_{\mathrm{t}} / \mathrm{K}_{\mathrm{t}}, \mathrm{l}=\Delta \mathrm{L}_{\mathrm{t}} / \mathrm{L}_{\mathrm{t}}$, respectively represent the annual growth rate of each element, then $\mathrm{y}=\mathrm{a}+\alpha \mathrm{k}+\beta l$. Then $\mathrm{y}-\alpha \mathrm{k}-$ $\beta l / y, \alpha \mathrm{k} / \mathrm{y}, \beta l / \mathrm{y}$ respectively represent the contribution rate of technological progress, capital and labor input to GDP growth. Use the formula to calculate the total factor productivity (that is, the contribution rate of technological progress) and the contribution rate of capital and labor input from 2000 to 2018, the results are as follows:

Table 3. The growth rates of production factors and their contribution rates from 2000 to 2018

\begin{tabular}{|c|c|c|c|c|c|c|}
\hline \multirow{2}{*}{ Year } & \multicolumn{3}{|c|}{ Average annual growth rate } & \multicolumn{3}{|c|}{ Contribution rate } \\
\hline & Total output Y & Capital K & Labor L & Labor L & Capital K & Technological progress $\mathrm{E}_{\mathrm{A}}$ \\
\hline 2000 & 4.86 & 4.07 & 4.87 & 16.26 & 393.06 & -309.32 \\
\hline 2001 & 4.95 & 4.18 & 4.87 & 16.27 & 403.79 & -320.07 \\
\hline 2002 & 5.03 & 4.25 & 4.89 & 16.34 & 410.43 & -326.77 \\
\hline 2003 & 5.12 & 4.34 & 4.89 & 16.34 & 419.48 & -335.82 \\
\hline 2004 & 5.23 & 4.46 & 4.85 & 16.21 & 430.83 & -347.04 \\
\hline 2005 & 5.33 & 4.56 & 4.91 & 16.39 & 440.54 & -356.93 \\
\hline 2006 & 5.43 & 4.67 & 4.91 & 16.41 & 451.87 & -368.29 \\
\hline 2007 & 5.52 & 4.83 & 4.93 & 16.47 & 466.59 & -383.06 \\
\hline 2008 & 5.62 & 4.94 & 4.94 & 16.48 & 477.85 & -394.33 \\
\hline 2009 & 5.59 & 4.90 & 4.92 & 16.45 & 473.81 & -390.25 \\
\hline 2010 & 5.67 & 4.96 & 4.93 & 16.46 & 479.58 & -396.04 \\
\hline 2011 & 5.78 & 5.04 & 4.93 & 16.48 & 487.44 & -403.92 \\
\hline 2012 & 5.83 & 5.10 & 4.94 & 16.51 & 492.90 & -409.40 \\
\hline 2013 & 5.85 & 5.13 & 4.94 & 16.51 & 495.74 & -412.26 \\
\hline 2014 & 5.90 & 5.14 & 4.95 & 16.52 & 497.13 & -413.65 \\
\hline 2015 & 5.92 & 5.14 & 4.95 & 16.54 & 497.12 & -413.66 \\
\hline 2016 & 5.93 & 5.17 & 4.95 & 16.55 & 499.61 & -416.16 \\
\hline 2017 & 5.96 & 5.20 & 4.95 & 16.55 & 503.10 & -419.65 \\
\hline 2018 & 6.02 & 5.25 & 4.96 & 16.55 & 507.02 & -423.57 \\
\hline
\end{tabular}

\section{Conclusions and recommendations}

It can be seen from the results that the growth of the Russian economy is driven by capital and labor inputs, of which capital investment plays a leading role, and innovation driven by scientific and technological progress is very small. During this period, although Russia increased its industrial structure adjustment efforts, the extensive economic growth mode that relied on resource exports did not undergo substantial changes compared with the past. Due to the inertia of the economic growth model, investment in fixed assets is still tilted towards the resource economy sector, leading to a weakening of investment in other industrial sectors. This is reflected in the capital contribution rate, that is, the economic growth driven by capital investment has a strengthening trend. In a short period of time, Russia Economic growth is still inseparable from a large amount of capital investment. The contribution rate of technological progress shows a negative economic growth effect as a whole. Although the downward trend has eased after 2014, Russia's innovation-driven economic development model has not yet formed. During this period, centering on the strategic goal of national innovation and development, the policies and regulations promulgated by the Russian government to encourage the development of the innovative economy were conducive to improving the country's innovation system and enhancing the country's innovation capabilities at the macro level. The crowding-out effect of the sector and the demand for resource export income of the innovative economy 
have caused Russia to struggle in the process of transitioning to an innovative economic model. It can be said that the risks and uncertainties of Russia's economic development prospects cannot provide a stable external environment for its innovation economy. At this stage, Russia's innovation economy development is still in its infancy. In view of this, Russia should base itself on its own reality, rely on the strength of traditional competitive industries to promote the development of the innovation economy, and at the same time give full play to the guiding role of policies, increase the reserve of innovative talents, build an economic innovation platform, and provide good conditions for enterprise innovation. In short, adjusting the relationship between the resource economy and the innovation economy, and implementing innovation development goals and innovation incentive measures are the keys to Russia's innovation economy strategy, and it is also the difficulties and challenges that the Russian government must solve and cope with to promote innovation and development.

\section{References}

[1] Tang Zhuchang. The Paradox of Economic Transition and Social Equity: Enlightenment from Russia[J]. Northeast Asia Forum, 2009, 18(1): 104-113.

[2] Li Yang. Analysis of Russian Economic Innovation Environment and Strategic Choices under the Conditions of Budget Constraints and Economic Sanctions[J]. Eurasian Economy, 2016, (4): 75-89.

[3] Xu Yuanfeng, Ren Gang. Analysis of Russia's "Innovative Economic Strategy" and Its Enlightenment to China[J]. Productivity Research, 2012(8):179-204.

[4] Diao Xiuhua, Guo Liancheng. Russia's innovative development strategy and its implementation effects[J]. Research on Financial Issues, 2015(7): 92-98.

[5] Xing Guofan, Zhang Shuxiao. Resource endowment, innovative economy and the future of Russia[J]. Northeast Asia Forum, 2012(3): 83-90.

[6] Ye Huijie. Research on Russian Innovation and Development[J]. Heilongjiang Science, 2018(8):156-157.

[7] Fu Jingyun. Russia's scientific and technological innovation capability and innovation performance evaluation[J]. Russian Journal, 2017, (5): 28-36.

[8] Sun Yanan, Wang Xiaoce, Liu Yan. Insist on innovation to lead development in the new era: internal logic and practical orientation[J]. Management Journal, 2019, 32(05):1-8.

[9] Robert M. Solow. A Contribution to the Theory of Economic Growth[J]. The Quarterly Journal of Economics, 1956,70(1): 65-94.

[10] Robert M. Solow. Technical Change and the Aggregate Production Function[J]. The Review of Economics and Statistics, 1957, 39(3): 312-320.

[11] Wang Zhongfu. The economic growth effect of scientific and technological progress since Russia's transformation[J]. Eurasian Economy, 2014(2): 35-44. 